\title{
The Relationship between Irrational Beliefs and Foreign Language Anxiety among Jordanian EFL Learners
}

\author{
Abdel-Rahman H. Abu-Melhim (Corresponding author) \\ Department of English Language and Literature, Irbid University College, Al-Balqa' Applied University, Irbid, Jordan \\ E-mail: abumelhim@hotmail.com \\ Mohammad H. Abood \\ Department of Special Education and Psychological Counseling, Ajloun National University, Ajloun, Jordan \\ Hamzeh M. Al-Zghoul \\ Department of English Language and Literature, Irbid University College, Al-Balqa’ Applied University, Irbid, Jordan \\ Rula M. Zughoul \\ Department of English Language and Literature, Irbid University College, Al-Balqa' Applied University, Irbid, Jordan
}

Received: 29-04- 2015

Published: 01-11- 2015
Accepted: 09-07- 2015

doi:10.7575/aiac.ijalel.v.4n.6p.130
Advance Access Published: August 2015

URL: http://dx.doi.org/10.7575/aiac.ijalel.v.4n.6p.130

\begin{abstract}
This study aimed at investigating the relationship between irrational beliefs and foreign language anxiety among a sample of (118) undergraduate students at Ajloun National University in Jordan. To achieve the purpose of the study, two scales were used: An irrational scale and an Arabic version of Horwitz and Cope's foreign language anxiety scale. The correlation descriptive method was used for data analysis. The results showed that there is statistically significant correlation between irrational beliefs and foreign language anxiety. Significant differences were found in the strength of relationship between irrational beliefs and foreign language anxiety according to gender in favor of meals. No Significant differences were found in the strength of relationship between irrational beliefs and foreign language anxiety due to academic level.
\end{abstract}

Keywords: Anxiety, Irrational Beliefs, Foreign Language Anxiety, University Students

\section{Introduction}

Thinking is considered as a means for humans to acquire knowledge and experiences that help them through selfrealization, completion of goals and control the course of life, thinking is a cognitive aspect that has received considerable attention in the field of counseling and psychotherapy, where many theoretical trends appeared of interest in the way people think and the impact on the emotional and behavioral side. Albert Ellis is considered among the leading scientists who were interested in this aspect through his known theory Rational Emotive Behavioral Therapy (REBT). Ellis, in his theory, supposes that behavior and emotion are two outputs for the individual's thinking, human thinking and emotions are not just two separated processes but are linked together, and what comes out of the individual's behavior or emotion is not just the response of individual to environmental conditions that only survives, but comes as a result of his ideas about environmental events (Dryden \& Ellis, 2001).

Ellis asserts that human is born and has prepared to be rational and irrational, so human can think in a logical way and fit with reality, and may think in distorted and twisted way that exaggerates things and amplify it and may feel very excited for trivial reasons (Bridges \& Harnish, 2010), when human adopts irrational beliefs he will be characterized by exaggeration intimidation in the interpretation of events; which leads him to hinder his daily life and causing the emergence of mental disorders.

Consequently irrational beliefs are defined as a set of perceptions and beliefs that are incompatible with reality and not objective and characterized by intimidation and exaggeration of events (Ellis, 1976), therefore irrational beliefs are considered as illogical beliefs and based on false expectations and generalizations characterized by subjectivity and lack of objectivity and affected by personal passions, they are a mix between probability and possibility and intimidation and exaggeration, which is not agreed with the realism of individual's potential. Ellis has identified eleven ideas considered irrational and responsible for mental disorders and lead to distortion and deviation in thinking and lack of compatibility between the self and the others, one of the irrational beliefs referred to Ellis "the individual should be on a level of competence and achievement to deserve appreciation". This idea and other irrational beliefs exist to a certain extent in all societies (Alrihani, 1985). There are many reasons behind these irrational beliefs like ignorance, sclerosis, intellectual stagnation, defensive methods and indifference (Shaheen \& Hamdi, 2007). 
In this regard, Ellis pointed to the form of $\mathrm{ABC}$, which he explains through it how emotional behavior and disorders occur based on what is adopted by the individual from beliefs and wrong and irrational ideas. Symbol (A) is an abbreviation of the term Activating Events and means the events and situations faced by the individual in his life and drives thinking, symbol (B) is abbreviation to the word Belief, which indicate how the individual explain events, symbol $(\mathrm{C})$ is an abbreviation of the word Consequences, which indicates the behavioral consequences of the individual to events and based on this model, the individual may misconstrue events by false and illogical beliefs which follows abnormal behavioral and emotional results (Ellis, 2000). Hence, it is necessary to intervene in the process of thinking that referred to Ellis symbol (B) and work to refute irrational beliefs about events and replace them with more rational ideas because individuals adopt unrealistic ideas lead to a lot of disorders and hinder them from achieving their goals, unlike the rational ideas that lead to the comfort and happiness and freedom from turmoil and conflicts and help to achieve the goals.

In light of changes taking place in contemporary life; there has been a clear change in the life of individuals and their behaviors and way of thinking, especially undergraduate students and they face a lot of events and situations that require conscious and logical thinking to overcome a lot of conflicts and frustrations that hinder the achievement of their goals. Youth in this stage have a great deal of ambition and openness to the outside world and more request for information and knowledge; which makes them adopt many of the ideas that may be illogical and unrealistic, so there must be more focus on irrational beliefs because of its role in the creation of emotional disorders among youth and anxiety in its all forms is considered one of these disorders. In this study, the researchers will identify a type of anxiety among undergraduate students with which irrational ideas may have a relationship namely English language learning anxiety.

\section{Purpose}

The study aimed to find out the relationship between irrational beliefs and foreign language anxiety among university students of both genders at Ajloun National University in Jordan. Specifically, the current study attempted to test the following hypotheses:

- There is a positive relationship statistically significant at the level of $(0.05 \geq)$ between irrational beliefs and English language anxiety at Ajloun National University students.

- There are statistically significant differences at the level of $(0.05 \geq)$ in the relationship between irrational beliefs and English language anxiety at Ajloun National University students due to the gender variable.

- There are statistically significant differences at the level of $(0.05 \geq)$ in the relationship between irrational beliefs and English language anxiety at Ajloun National University students due to the classification variable.

\section{Problem Statement}

There are a lot of events and situations that university students face which may cause them to feel anxious and suffer from an internal conflict. When the students adopt ideas that are not rational to situations that they pass by, this will impact on their effectiveness and their ability to fulfill their potential and accomplish their goals, where a number of studies indicate that irrational beliefs among university students play a big role in reducing their efficiency, productivity and academic performance.

Foreign language anxiety is considered as one of the emotional disorders that is often deployed among learners of the language and university students in particular, many of them complain of the symptoms that may be severe and disabling for students to acquire and learn a second language, where the researchers noted as being one of the university staff this kind of anxiety which is spread among students through many behaviors come from their side as the refuse to read some of the terms in English language because they fear negative evaluation or exposure to ridicule from others as a result of their mistakes, as well as their repeated requests not to include any of the terms in English language in the exams and other behaviors that avoid them learn foreign language. It may be to avoid such situations by the students refer back to their irrational and non-objective interpretation towards it; which makes them vulnerable to conflicts and emotional unrest including this type of anxiety, which relates to learning a foreign language, particularly English language, which is the second official language in Jordan and often stops accepting students in universities or competition to get a job to pass the test for this language. On the other hand, theoretical literature indicates the lack of studies that attempt to investigate the relationship between irrational beliefs and foreign language anxiety. This justifies the current study in order to investigate this relationship on a representative sample of Jordanian university students.

\section{Limitations}

The study was limited to undergraduate students at Ajloun National University in Jordan who are registered in the first semester of the academic year 2014-2015. Accordingly, the results will be limited to the population of the study and similar communities.

\section{Significance}

The importance of the study stems from the fact that it relates to a significant component of society namely university students, where this study contributes to the identification of the role of irrational beliefs and how they relate to emotional disorders including foreign language anxiety among university students in light of gender and academic level variables taking the following into consideration: 
- Work to refute and correct the irrational and illogical ideas about foreign language learning among university students.

- Discover the individuals who suffer from foreign language anxiety and help them to get self- confidence and get rid of the problems that hinder the learning process.

- Contribute to pay attention to researchers and those who are in charge of the educational process to design more, preventive and therapeutic programs that is appropriate to reduce the impact of foreign language anxiety and work to raise the level of performance.

- It is hoped that this study will be a new platform for scientific and educational research in the area of foreign language anxiety.

\section{Definitions}

- Irrational Beliefs: They are incorrect beliefs and opposite of reality and logic toward events and lead to emotional and behavioral disorders (Ellis, 1976), and are measured in this study by irrational beliefs scale prepared by the researchers.

- Foreign Language Anxiety: Is a set of physiological, behavioral and cognitive responses associated with the feeling of the individual as a result of the negative expectations of failure in the performance of learning a foreign language and it is measured in this study through language anxiety scale that the researchers adapted.

\section{Methodology}

The study used a descriptive approach. Also, it attempted to identify the relationship between irrational beliefs and foreign language anxiety and whether the relationship varies depending on the gender of the student and educational level.

\subsection{Study Population}

Population of the study consisted of all undergraduate students at Ajloun National University in Jordan who attended school during the first semester of the academic year 2013/2014. The number of the study population has reached (1440) students.

\subsection{Study Sample}

Sample of the study consisted of (118) male and female students at Ajloun National University and they have been chosen randomly. The distribution of the sample depends on the study level, which is divided into two levels: The first includes students of the first and second years, and the second includes the students of the third and fourth years in addition to the gender variable.

\subsection{Study Instruments}

The researchers used two different scales to achieve the goals of the study. The scales are:

\subsubsection{Irrational Beliefs Scale:}

After careful revision of published scales (Alrihani, 1985) \& (Shaheen and Hamdi, 2007). Irrational beliefs scale was developed by adding more irrational beliefs to the original scale which would be appropriate to university level students since some scales were built to suit different study samples other than university students, while other scales were applied to other environments that do not include Jordan. Therefore, the scale developed by the researchers in its final form consisted of (15) items.

In order to verify content reliability for irrational beliefs scale the scale was shown in its initial form which consisted of (18) items to seven faculty members for evaluation. These faculty members are specialists in the fields of educational psychology and evaluation and measurement at different Jordanian universities. They were asked to evaluate the scale in terms of language and appropriateness to the study sample. After receiving the feedback from the evaluators, three items were deleted from the scale. Therefore, the scale consisted of (15) items in its final form (see appendix A).

\subsubsection{Foreign Language Classroom Anxiety Scale:}

This scale evaluates the different anxiety situations for students learning English as a foreign language (see appendix B).

The researchers translated the original language anxiety scale from English into Arabic. The scale was then evaluated by a number of specialists in the areas of educational psychology, psychological counseling and English language. They were all requested to offer their opinions regarding language style, clarity of meaning and any other modifications they may feel necessary based on their experience and knowledge. The items on the scale were modified according to the comments and suggestions of the reviewers.

For purposes of this study, the authors used the foreign language anxiety scale (Horwitz, et al., 1986). The scale consisted of (33) items. Then distributed to participants who were asked to respond in a 5-level gradual grading system $(0=$ strongly disagree $-5=$ strongly agree $)$. The lowest score on the scale is; therefore, 0 , while the highest score was 165.

The foreign language anxiety scale may be described as a scale which measures the level of anxiety of learners in a situation where they attempt to learn English as a foreign language. 


\section{Results}

Pearson's correlations were used to verify the validity of the first hypothesis. In addition, the values of "Z" and partial correlation were used to verify the validity of the second and third hypotheses.

Table 1. Repetition and percentages according to study variables.

\begin{tabular}{cccc}
\hline Variable & Group & Repetition & Percentage \\
\hline \multirow{2}{*}{ Gender } & Male & 50 & 42.4 \\
& Female & 68 & 57.8 \\
& Total & 118 & 100.0 \\
& Freshman & 61 & 51.7 \\
\multirow{2}{*}{ Educational level } & Sophomore & & 48.3 \\
& Junior & 57 & 100.0 \\
\hline
\end{tabular}

This study attempted to test a number of hypotheses about the relationship between life pressures and academic procrastination for university level students. To verify the first hypothesis which claims that there is a positive statistically significant relation at $(\alpha \leq 0.05)$ between irrational beliefs and English language anxiety for Ajloun National University students. Pearson's correlation variable was calculated as shown in table 2.

Table 2. Pearson's correlation between irrational beliefs and English language anxiety

\begin{tabular}{ccc}
\hline & & English Language Anxiety \\
\hline \multirow{3}{*}{ Irrational Beliefs } & "R" Correlation Variable & $0.541(* *)$ \\
& Significance & 0.000 \\
& Number & 118 \\
\hline
\end{tabular}

(*) Statistically significant at $(0.05)$

(**) Statistically significant at (0.01)

Table 2 shows that there is a positive statistically significant relation between irrational beliefs and English language anxiety for Ajloun National University students.

To verify the validity of the second hypothesis which is related to the existence of statistically significant differences at $(\alpha \leq 0.05)$ between irrational beliefs and English language anxiety for Ajloun National University students which are due to the variable of gender, the correlations between irrational beliefs and English language anxiety were calculated according to the gender variable. The value of " $Z$ " was also calculated to figure out the differences in the correlation between the groups of this particular variable as shown in table 3 .

Table 3. Correlation variables between irrational beliefs and English language anxiety according to gender and " $Z$ " test.

\begin{tabular}{ccccc}
\hline & & "R" & Number & "Z" \\
\hline \multirow{2}{*}{ Gender } & Male & $0.473(* *)$ & 50 & \multirow{2}{*}{0.131} \\
& Female & $0.498(* *)$ & 68 & \\
\hline
\end{tabular}

Table 3 shows that there is no statistically significant difference $(\alpha=0.05)$ in the correlation between irrational beliefs and English language anxiety due to the gender variable.

To verify the validity of the third hypothesis which is related to the existence of statistically significant differences at ( $\alpha$ $\leq 0.05)$ between irrational beliefs and English language anxiety for Ajloun National University students which are due to the variable of educational level, the correlations between irrational beliefs and English language anxiety were calculated according to the first educational level (freshman \& sophomore) and the second educational level (junior \& senior). The value of "Z" was also calculated to figure out the differences in the correlation between the groups of this particular variable as shown in table 4 .

Table 4. Correlation variables between irrational beliefs and English language anxiety according to educational level and "Z" test.

\begin{tabular}{|c|c|c|c|c|}
\hline & & "R" & Number & "Z" \\
\hline \multirow{2}{*}{ Educational level } & Freshman & $0.675(* *)$ & 61 & \multirow[b]{2}{*}{$2.078^{*}$} \\
\hline & $\begin{array}{l}\text { Junior } \\
\text { Senior }\end{array}$ & $0.282(* *)$ & 57 & \\
\hline
\end{tabular}


Table 4 shows that there is a statistically significant difference $(\alpha=0.05)$ in the correlation between irrational beliefs and English language anxiety due to the educational level variable in favor of the first level

There are several studies that pointed to the correlation between irrational beliefs and emotional disorders for individuals. For example, (Hassan \& Jammali, 2003) conducted a study that pointed to the existence of a correlation between irrational beliefs and emotional disorders represented in depression, confusion anxiety and the feeling of alienation.

Another study (Deepika \& Nutankumar, 2007) pointed to the existence of a positive relation between irrational beliefs and anger. Moreover, a study conducted by (Kamae \& Weisani, 2014) pointed to the existence of a statistically significant positive correlation between social anxiety and irrational beliefs.

\section{Discussion}

Many studies dealing with irrational beliefs and their relationship with some variables among students were conducted, in contrast few studies shows that foreign language anxiety, especially in the Arab environments, and here a number of studies that have addressed all of the irrational beliefs and foreign language anxiety:

Farah, et al (1993) conducted a study aimed to identify the relationship between the test anxiety and irrational ideas, the sample consisted of (292) students from high school students in Irbid, Jordan and the researchers used irrational beliefs measure in addition to Swain measurement for test anxiety. The study results showed that there statistically significant differences between the mean scores of students on test anxiety and between the mean scores of students on irrational beliefs scale.

Hassan \& Al-Jammali (2003) conducted a study aimed to recognize the irrational beliefs and their relationship with some emotional variables in a sample of Sultan Qaboos University students. The sample consisted of (204) students on whom the irrational beliefs, depression, anxiety as a trait, test anxiety and alienation scales were applied. The results indicated the prevalence of irrational ideas among university students also the results indicated that there is a relationship between irrational beliefs and emotional disorders and the lack of gender effect on the spread of these ideas.

In a study conducted by Al-Sabaah and Al-Hmouz (2007) to identify the irrational beliefs and their relationship with some variables in a sample consisted of (604) students from the West Bank university students in Palestine and they used irrational beliefs scale. The results showed the prevalence of irrational beliefs among university students and the presence of statistically significant differences in the prevalence of irrational beliefs attributed to gender and in favor of males while the results did not show differences due to the variables of residence, university and specialization.

Shaheen and Hamdi (2007) conducted a study aimed to investigate the relationship between the degree of self-esteem and irrational thinking for a sample consisted of (249) male and female students at Al-Quds Open University and researchers used a scale of rational and irrational beliefs and a scale of self-esteem. The study results revealed the existence of negative correlation relation between irrational thinking and self-esteem among students both male and female.

Deepika and Nutankumar (2007) conducted a study aimed to find out the relationship between anger and irrational beliefs for couples in different places of India. The study included a sample consisted of (152) couples. The study revealed that there is a positive relationship between anger and irrational beliefs.

Al-Owaidhah (2008) conducted a study aimed to find out the relationship between the rational and irrational beliefs and levels of mental health for a sample of Amman Private University students. The sample consisted of (181) students using a scale of rational and irrational beliefs and a scale of public health. The results revealed the prevalence of irrational beliefs in for the sample of the study and the lack of statistically significant differences in all irrational beliefs due to the variable of gender except the fifth idea which is associated with emotional recklessness in favor of males.

Also Kamae and Weisani (2014) conducted a study to investigate the relationship between social anxiety and irrational beliefs and social intelligence for the students who had homesickness at Tehran University. The sample consisted of (235) students. The study used social anxiety, irrational beliefs, emotional intelligence and homesickness scales. The results of the study showed a statistically significant positive relationship between social anxiety and irrational beliefs as well as a significant negative correlation between emotional intelligence and homesickness.

In a study, Khorasani and Babaei (2014) aimed to identify the relationship between irrational beliefs and psychological security and quality of life for university students in Iran. The sample of the study consisted of (342) students. The study used Jones 1986 test for irrational beliefs and psychological security scale and quality of life scale. The results showed that there is a negative relationship between irrational beliefs and psychological security and quality of life.

Regarding the studies that addressed foreign language anxiety, Szyszka (2011) conducted a study aimed to identify the relationship between anxiety and oral performance of foreign language for a sample composed of (48) individuals learning English as a foreign language in Poland. The results revealed that there is a negative correlation between anxiety and the ability to pronounce the English language correctly.

In a study conducted by Melouah (2013) aimed to identify the nature of the foreign language anxiety and sources of this anxiety among graduate students at Saad Dahlab University in Algeria. The study used the scale designed by (Horwitz, et al., 1986) for foreign language anxiety. The results indicated that the reasons beyond this anxiety are lack of selfconfidence and lack of self-esteem and fear of making mistakes during the pronunciation. 
Arnaiz and Guillén (2012) conducted a study aimed to identify the relationship between foreign language anxiety and gender and age of the individuals who are learning English as a foreign language in Spain. The sample of the study consisted of (216) people. They used the scale designed by (Horwitz, et al., 1986) for foreign language anxiety. The results indicated the presence of anxiety in a higher level for females compared with males and also appeared higher among students from basic levels compared with advanced levels.

Tsai and $\operatorname{Li}(2012)$ conducted a study to identify the impact of foreign language anxiety and test anxiety in competency of reading a foreign language. The sample consisted of newly registered students in English as a foreign language in Taiwan, they were 304 students. The study used the test anxiety scale and the foreign language anxiety scale. The results of the study revealed that there is a negative relationship between anxiety and reading proficiency in foreign languages.

Through a review of the results of the previous studies that discussed irrational beliefs and foreign language anxiety, we observe that it is agreed upon the prevalence of these two variables among students. Moreover, these studies have shown statistically significant positive relationships between irrational beliefs and a number of abnormal variables such as emotional disorders, anger and test anxiety and a negative relationship between irrational beliefs and some normal variables such as self-esteem and psychological health. It should be noted that the results of studies related to irrational beliefs and foreign language anxiety with respect to gender and academic level were contradictory.

As may be seen from reviewing the results of previous studies that specifically addressed foreign language anxiety, the scarcity of these studies particularly in the Arab environments and the environment of Jordan becomes very obvious. In addition, the researchers were unable to find any studies related to foreign language anxiety in the Jordanian environment. The researchers did not find any study which addressed the relationship between irrational beliefs and foreign language anxiety among university students.

\subsection{Foreign Language Anxiety}

Language plays an important role in the lives of human beings as a means of social communication and to express the ideas and emotions, and language is characterized as a feature of humanity because it seeks to serve human beings and to achieve their objectives, and it is linked to their social, intellectual and cultural development. The language is considered as a regular set of verbal symbols through which the members of human community can contact. Also, language is considered as an acquired behavior, because the individual is born without any knowledge of the language but he or she has the ability and willingness to learn the language, and from here comes the role of the social environment and regular education to make the language acquired. The individual learns his or her mother tongue at an early age because they are in normal conditions and become an integral part of his growth cognitive, social and behavioral maturity and it is the means by which to deal and merge with the community, and the inevitable result is that the individual is fully proficient in the language, but it's different to learn a second language because it is not an essential part in the process of his growth and maturity.

Moreover, second language learning usually happens under formal conditions inside the school and is different from learning the mother tongue which happens naturally. As a result, the individual does not obtain the same amount of exposure to the language and its uses (Ellis, 1998). There are other factors that have an impact on the process of learning a second language, including the age at which he or she has been learning a foreign language. In language learning, there is a critical period for the acquisition of language, and it is a specific period of life identified biologically through which language acquisition will be relatively easy. Language acquisition becomes more difficult later due to the flexibility of the brain before the age of puberty. This is what enables the individual to acquire the language and then it becomes difficult for the learner to master the language system, especially the audio system (Singleton \& Lengyel, 1995).

Factors that affect foreign language learning include: Intelligence, learning strategies, motivation beyond the goal of learning and outputs (Al-Damegh, 2011). Also, emotional variables are considered among the factors that have a significant impact on foreign language learning, including anxiety that forms a barrier to learn and acquire second language acquisition, where many studies discuss the role of anxiety and its negative impact on the performance of students in learning a foreign language (Supon, 2004). In this regard, (Krashen, 1981) points that there is an inverse relationship between anxiety and the ability to learn a foreign language. The more anxiety, the learner will reduce susceptibility to learn and acquire second language, while less anxiety will increase susceptibility to learn that language.

It should be noted that anxiety is normal in its normal limits but if it exceeds these limits and arrive to a sharp level, it affects the individual's ability and effectiveness and becomes a disease (Chapell \& Blanding, 2005). Anxiety is defined as an unpleasant emotional experience when the individual feels discomfort, instability and fear when exposed to frustrating situations (Spielberger, 1983). Also, it may be defined as a state of stress in the cognitive, emotional, behavioral and physiological dimensions (Scholing \& Emmelkamp, 1993).

Moreover, anxiety is considered as a state of discomfort and uneasiness accompanied by physiological responses such as accelerated heart beats and repetitive breathing, and behavioral responses such as poor performance and avoidance of certain situations (Barlow, 2001). There are two types of anxiety mentioned by Cattell and Spielberger namely: Anxiety state, which is the case of emotional emergency connected to a specific time and disappears when the variables that inspire it disappear. The second is anxiety trait, which is considered as a personal attribute that is relatively constant (Spielberger, et al., 1970). 
There are various reasons for anxiety that are related to the point of views of the scientists and their theoretical attitudes. According to Freud, anxiety is related to the instincts that he considered as the basis for the occurrence of anxiety. According to Adler, anxiety is related to the shortage of feelings in the individual, whether it was physical, psychological, social, economical or cultural. However, Sullivan considers anxiety as a result of disorders in the mutual relations between the individual and the community in which he or she lives, to agree with Karen Horney, who attributed anxiety to the social and cultural factors. The two behavioral psychologists have considered anxiety as an educated response from the environment, while other scientists believed that the main component of anxiety is the way of individual thinking toward events that he or she is exposed to (Strongman, 1995).

Anxiety is accompanied by different symptoms. There are physical symptoms as shivering, muscle tension, accelerated heart beats, sweating, cold hands, dry throat and nausea. Cognitive symptoms include the difficulty of concentration, attention and cognition (American Psychiatric Association, 2013). Anxiety varies according to the diversity of its subjects or exciting positions for anxiety. There are different types of anxiety which include: Future anxiety, marital anxiety, death anxiety, social anxiety and test anxiety. Other types of anxiety appear in different situations when individuals are exposed to them with varying degrees of severity, including students who are exposed to anxiety as a result of scientific and psychological pressures that they face in different life situations, including the process of learning a foreign language.

Horwitz, et al., (1986) are considered the first scientists who pointed to foreign language anxiety it is one of the types of anxiety that appears during learning foreign languages. Foreign language anxiety is known as an emotional state accompanied by particular physiological and behavioral aspects which appear on the individual in the process of learning other languages (Pawanchik, et al., 2010). Anxiety is considered as one of the variables affecting the success of the process of learning a foreign language, as it is considered as one of the factors that highlight individual differences in the process of learning for the learners (Horwitz, 2001). Anxiety leads to poor performance and low efficiency in learning a foreign language (Calvo \& Alamo, 1987).

Anxiety appears as a crucial and influential factor in a negative manner in terms of language acquisition and in the process of practicing the language orally. Students who feel anxiety while learning a foreign language do not feel comfortable when performing language and thus prefer silence and monitoring others while speaking a foreign language (Mohamad \& Wahid, 2009). In a study conducted on Chinese students, who are learning English, the study showed that anxiety was one of the most significant factors influencing the process of learning language (Yu, 2010). In another study on learners of Arabic language by American students, the study found that anxiety was associated negatively with achievement and the ability to learn a foreign language $(\mathrm{Hu}, 2003)$. Foreign language anxiety often appears clearly in audio and oral performance of language learners (Young, 1991).

Opinions vary over the classification of foreign language anxiety types. According to types of anxiety including: Public anxiety, social anxiety, attribute anxiety and state or communication anxiety. Anxiety was viewed by some as a kind of social phobia because of the large social interaction associated with it (MacIntyre \& Gardner, 1994). Most scientists agreed that this type of anxiety falls under state anxiety through a specific experience (Kitano, 2001). As MacIntyre indicates (1999) foreign language anxiety is one of the types of specific anxiety which relates to the environment of foreign language learning. Scovel (1978) states that there are two types of anxiety with regard to learning a foreign language namely: Beneficial anxiety which is positive and useful and works to raise the motivation of learners to acquire a foreign language and increases their self-confidence in the learning process. The second type is harmful anxiety which has negative effects on the performance of foreign language learners.

There are several reasons for foreign language anxiety, where (Ely, 1986) sees that the teaching style and the limited time allocated for learners and the absence of native speakers of a foreign language are some of the main reasons that lead to the anxiety of foreign language. Jackcon (2001) indicates that the factors that stimulate foreign language anxiety are classified into two categories: Special factors by the learning process and special factors by the learners. The one related to the learning process includes activities associated with learning and teaching methods and factors related to the learners that include variables such as: Age, culture, gender and personality traits. Other sources of foreign language anxiety include false beliefs formed by the individual towards the process of learning a foreign language such as: Fear of good performance or inability to speak fluently with a perfect accent and beliefs or reactions of others toward mistakes while learning the language (Horwitz, et al., 1986).

There are negative effects for foreign language anxiety on the learners who lose their self-efficacy that is necessary to reach a high level of mastery and excellence in performance. As indicated by (MacIntyre, 1999), academic and cognitive effects come as a result of foreign language anxiety. From the academic side of foreign language anxiety, the result will be inability to pronounce words properly or inability to use grammar correctly, as well as low performance and achievement on learning a foreign language (Krashen, 1981). From the cognitive side, the result will be the lack of ability to process information in the expected speed and not being able to keep the vocabulary in memory and dispersion in attention and weakness in focus.

Based on the above, we note that anxiety is the main challenge that accompanies the process of learning a second language as it increases the feeling of incompetence or inability to achieve on the part of the learners.

\section{Conclusion}

Based on the findings of the previously reviewed studies and similar studies in the field, the following findings may be summarized: 
- Irrational beliefs are strongly associated with the negative aspects of individuals including English language learning anxiety.

- Irrational beliefs tend to control individuals and push them towards extremism and away from reality in interpreting and evaluating matters. This results in the creation of different emotional disorders including English language learning anxiety.

- $\quad$ English language learning is considered among the subjects that could be viewed in an irrational manner by EFL learners as a result of adopting negative beliefs regarding learning and acquiring this language without any regard to gender.

- Some EFL learners may reach the conclusion that learning a foreign language such as English is an impossible task which inevitably leads to failure in the language learning or acquisition process.

- Freshman and sophomore college students seem to have a higher level of foreign language anxiety since they have not yet realized the reality surrounding the learning process of English or its importance. Such lower level college students do not usually posses the necessary skills associated with language learning compared to their junior and senior level counterparts.

\subsection{Recommendations}

Based on the results and conclusions discussed above, the following recommendations may be reached:

- Rational Emotive Behavior Therapy (REBT) should be used in group counseling to reduce the level of anxiety for students learning English as a foreign language based on the effectiveness of this method exemplified in various studies (Abood \& Abu-Melhim, 2015a), for example.

- Systematic desensitization should be used in group counseling to reduce the level of anxiety for students learning English as a foreign language based on the effectiveness of this method exemplified in various studies (Abood \& Abu-Melhim, 2015b), for example.

- $\quad$ Further research dealing with foreign language anxiety should be conducted since studies in this area are relatively scarce. Furthermore, the level of seriousness for the spread of foreign language anxiety should be investigated in order to find better ways to treat it.

- Professional training courses should be held for educational and psychological counselors in order to foster their knowledge and abilities in using special methods and treatment programs to reduce and overcome foreign language anxiety.

\section{References}

Abood, M. \& Abu-Melhim, A. (2015a). Examining the effectiveness of group counseling in reducing anxiety for Jordanian EFL learners. Journal of Language Teaching and Research, 6, 4, (forthcoming).

Abood, M. \& Abu-Melhim, A. (2015b). Investigating the effectiveness of systematic desensitization in reducing anxiety for Jordanian EFL learners. Paper presented at the International conference: Innovation in teaching and learning English: New methods and approaches held in Bejaia, Algeria, April 21-22, University of Bejaia.

Al-Damegh, K. (2011). The Most Appropriate Age for Teaching Foreign Languages, Riyadh, Saudi Arabia: Madar AlWatan Publishing House.

Al-Owaidhah, S. (2008). The relationship between rational and irrational beliefs and the levels of psychological health among a sample of Amman Private University students. Gulf Message Journal, 113, 1, 109-155.

Alrihani, S. (1985). Developing the test of rational and irrational beliefs. Studies in Educational Sciences, 12, 11, $77-95$.

Al-Sabaah, S. \& Al-Hmouz, A. (2007). Irrational beliefs and their relation to some variables among West Bank universities in Palestine. University Arab league Journal, 14, 1, 2-17.

American Psychiatric Association (2013). Diagnostic and statistical manual of disorders (DSM-5). Washington, DC: American Psychiatric Association.

Arnaiz, P. \& Guillén, F. (2012). Foreign language anxiety in a Spanish university setting: interpersonal differences. Revista De Psicodidàctica, 17, 1, 5-26.

Barlow, D. H. (2001). Anxiety and its disorders: The nature and treatment of anxiety and panic. New York: Guilford Press.

Calvo, M. \& Alamo, L. (1987). Test anxiety and motor performance the role of muscular and intentional demands antinational demands. International Journal of Psychology, 22, 2, 165-178. DOI: 10.1080/00207598708246775.

Chapell, S. \& Blanding, B. (2005). Test anxiety and academic performance within undergraduate and graduate students. Journal of Educational Psychology, 97, 2, 268-274.

Deepika, M. \& Nutankumar, S. (2007). Role of anger and irrational thinking on minor physical health problems among marital couples. Journal of the Indian Academy of Applied Psychology, 33, 1, 119-128.

Dryden, W. \& Ellis, A. (2001). Rational behavior therapy. New York: Guilford Press. 
Bridges, K. \& Harnish, R. (2010). Role of irrational beliefs in depression and anxiety: A review. Health, 2, 8, $862-877$. DOI: $10.4236 /$ health.2010.28130.

Ellis, A. (2000). How to maintain and enhance your rational-emotive therapy gains. New York: The Institute for Rational-Emotive Therapy.

Ellis, R. (1998). Second language acquisition. Oxford University Press: Oxford.

Ellis, A. (1976). The biological basis of human irrationality. Journal of Individual Psychology, 32, 145-168.

Ely, C. (1986). An analysis of discomfort, risk taking, sociability and motivation in the L2 classroom. Language Learning, 36, 1-35.

Farah, A., Al-Otoum, A. \& Al-Ali, N. (1993). Test anxiety and rational and irrational beliefs. Journal of Psychology, $26,7,26-32$.

Hassan, A. \& Al-Jammali, F. (2003). Irrational beliefs and their relation to some emotional variables. Journal of Educational Sciences, 4, 1, 195-231.

Horwitz, E. (2001). Language anxiety and achievement. Annual Review of Applied Linguistics, 21, 112-126. DOI: $10.1017 / \mathrm{S} 0267190501000071$.

Horwitz, E. K., Horwitz, M. B. \& Cope, J. (1986). Foreign language classroom anxiety. The Modern Language Journal, 70, 2, 125-132. DOI: $10.2307 / 327317$.

Hu, C. F. (2003). Phonological memory, phonological awareness and foreign language word Learning. Language Learning, 53, 429-462. DOI: 10.1111/1467-9922.00231.

Jackcon, J. (2001). Reticence in second language case discussions: Anxiety and a aspiration. System, 30, 65-84.

Kamae, A. \& Weisani, M. (2014). The relationship between social anxiety irrational beliefs and emotional intelligence with homesickness in dormitory students of Tehran University. Indian Journal of Fundamental and Applied Life Sciences, 4, 1, 285-292.

Khorasani, F. \& Babaei, M. (2014). Evaluating the relationship between irrational beliefs and psychological security and quality of life among students. Reef Resources Assessment And Management Technical Paper, 40, 1, $186-194$.

Kitano, K. (2001). Anxiety in the college Japanese language classroom. The Modern Language Journal, 85, 4, 549-566. DOI: $10.1111 / 0026-7902.00125$.

Krashen, S. D. (1981). Second language acquisition and second language learning. Oxford: Pergamon Press.

MacIntyre, P. D., (1999). Language Anxiety: A review of the Research for Language Teachers. In: D. J. Young (Ed.), Affect in foreign language and second language learning. New York: McGraw-Hill Companies.

MacIntyre, P. D. \& Gardner, R. C. (1994). The Effects of induced anxiety on three stages of cognitive processing in computerized vocabulary. Studies in Second Language Acquisition, 16, 1, 1-17. DOI: 10.1017/S0272263100012560.

Melouah, A. (2013). Foreign language anxiety in EFL speaking classrooms: a case study first- year LMD students of English at Saad Dahlab University of Blida, Algeria. Arab World English Journal, 4, 1, 64-76.

Mohamad, A. \& Wahid, N. (2009). Anxiety and speaking English as a second among male and female business students in university industry Selangor. Segi Review, 2, 2, 65-84.

Pawanchik, S., Kamil, A. \& Yahaya, F. (2010). Indigenous students and the learning of English. Foreign Language Annals, 32, 63-76.

Scholing, A. \& Emmelkamp P. M. (1993). Exposure with and without cognitive therapy for generalized social phobia: Effects of individual and group treatment. Behavior Research Therapy, 31, 667-681. DOI: 10.1016/00057967(93)90120-J.

Scovel, T. (1978). The effect of affect foreign language learning: A review of the anxiety research. Language Learning, $28,42-129$.

Shaheen, M. \& Hamdi, N. (2007). The level of self-esteem for Palestinian university students: The relation to irrational thinking and the effect of rational emotional behavior therapy in its development. Open Jerusalem University Journal, $16,14,11-60$.

Singleton, D. \& Lengyel, Z. (1995). The Age Factor in Second Language Acquisition, Clevedon, UK: Multilingual Matters.

Spielberger, C. (1983). Manuel for the State-Trait Anxiety Inventory, Palo Alto, Calif.: Consulting Psychologists Press.

Spielberger, C., Gorsuch, R. \& Lushene, R. (1970). Manual for the sate-trait anxiety inventory. Palo Alto, CA: Consulting Psychologists Press.

Strongman, K. T. (1995). Theories of anxiety. New Zealand Journal of Psychology, 24, 2, 4-10.

Supon, V. (2004). Implementing strategies to assist test anxious students. Journal of Instructional Psychology, 31, 4, 292-296.

Szyszka, M. (2011). Foreign language anxiety and self-perceived English pronunciation competence. Studying in Second Language Learning and Teaching, 1, 2, 282-300. 
Tsai, Y. \& Li, Y. (2012). Test anxiety and foreign language reading anxiety in a reading- proficiency test. Journal of Social Science, 8, 1, 95- 103.

Young, D. (1991). Creating a low-anxiety classroom environment: What does language. Anxiety research suggest? Modern Language Journal, 75, 426-439.

Yu, B. (2010). Learning Chinese abroad: The role of language attitudes and motivation in the adaptation of international students in China. Journal of Multilingual Development, 31, 3, 201-321.

\section{Appendix A: Irrational beliefs scale}

[1] I refuse the results of works that come against my expectations \begin{tabular}{l|c|c} 
Strongly Agree & Agree & Neither Agree Nor Disagree
\end{tabular}

\begin{tabular}{l|l} 
Disagree & Strongly Disagree \\
\hline
\end{tabular}

[3] I believe that an individual's past determines his or her present and future behavior

\begin{tabular}{l|l|l|l|l} 
Strongly Agree & Agree & Neither Agree Nor Disagree & Disagree & Strongly Disagree
\end{tabular}

$[4]$ \begin{tabular}{l|l|l} 
Strongly Agree & Agree & Neither Agree Nor Disagree
\end{tabular}

\begin{tabular}{|l|c|c} 
Disagree & Strongly Disagree \\
\hline ept. & Disagree & Strongly Disagree \\
\hline
\end{tabular}
I feel annoyed when I behave in a way that others do not accept.

[5] \begin{tabular}{l|l|l} 
Strongly Agree & Agree & Neither Agree Nor Disagree
\end{tabular}

$[6]$ I prefer to avoid failure instead of facing it. \begin{tabular}{l|l|l} 
Strongly Agree & Agree & Neither Agree Nor Disagree
\end{tabular}

\begin{tabular}{l|c|c|}
\multicolumn{2}{|c|}{ Disagree } & Strongly Disagree \\
\hline & Disagree & Strongly Disagree \\
\hline
\end{tabular}

[7] I feel fearful when things go in a way other than what I desire. \begin{tabular}{l|l|l} 
Strongly Agree & Agree & Neither Agree Nor Disagree
\end{tabular} I realize that pleasing everyone is an impossible mission. [8] I feel frustrated when I fail to accomplish a task at the first attempt.

[9] I am always extremely concerned about what others think about me. \begin{tabular}{l|c|c|c|c} 
Strongly Agree & Agree & Neither Agree Nor Disagree & Disagree & Strongly Disagree
\end{tabular} \begin{tabular}{l|c|c|} 
Strongly Agree & Agree & Neither Agree Nor Disagree \\
\hline
\end{tabular}

\begin{tabular}{|l|l}
\hline Disagree & Strongly Disagree \\
\hline
\end{tabular}

[10] I feel extremely annoyed when I find myself in situations where I am not superior to others.

\begin{tabular}{|c|c|c|c|c|}
\hline Strongly Agree & Agree & Neither Agree Nor Disagree & Disagree & Strongly Disagree \\
\hline
\end{tabular}

[11] I fail despair when I cannot find solutions to my problems.

\begin{tabular}{|c|c|c|c|c|}
\hline Strongly Agree & Agree & Neither Agree Nor Disagree & Disagree & Strongly Disagree \\
\hline
\end{tabular}

[12] I expect failure towards the tasks I am asked to perform. \begin{tabular}{|c|c|c|c|c|}
\hline Strongly Agree & Agree & Neither Agree Nor Disagree & Disagree & Strongly Disagree \\
\hline
\end{tabular}

[13] I feel that there is only one chance for success for each individual. \begin{tabular}{|c|c|c|c|c|}
\hline Strongly Agree & Agree & Neither Agree Nor Disagree & Disagree & Strongly Disagree \\
\hline
\end{tabular}

[14] I feel that the way others judge my performance is the standard by which my success is measured. \begin{tabular}{|c|c|c|c|c|}
\hline Strongly Agree & Agree & Neither Agree Nor Disagree & Disagree & Strongly Disagree \\
\hline
\end{tabular}

[15] I exaggerate when I expect bad things are about to happen.

\begin{tabular}{|c|c|c|c|c|}
\hline Strongly Agree & Agree & Neither Agree Nor Disagree & Disagree & Strongly Disagree \\
\hline
\end{tabular}


[1] I never feel quite sure of myself when I am speaking in my foreign language class. \begin{tabular}{l|c|c|c} 
Strongly Agree & Agree & Neither Agree Nor Disagree & Disagree
\end{tabular} I don't worry about making mistakes in language class. \begin{tabular}{l|l|l|} 
Strongly Agree & Agree & Neither Agree Nor Disagree \\
\hline
\end{tabular} \begin{tabular}{l|l|l}
\hline Disagree & Strongly Disagree \\
\hline
\end{tabular} I tremble when I know that I'm going to be called on in language class.

[4] It frightens me when I don't understand what the teacher is saying in the foreign language. \begin{tabular}{l|l|l|} 
Strongly Agree & Agree & Neither Agree Nor Disagree
\end{tabular} It wouldn't bother me at all to take more foreign language classes. \begin{tabular}{|l|c|c|c|c|} 
Strongly Agree & Agree & Neither Agree Nor Disagree & Disagree & Strongly Disagree
\end{tabular} During language class, I find myself thinking about things that have nothing to do with the course.

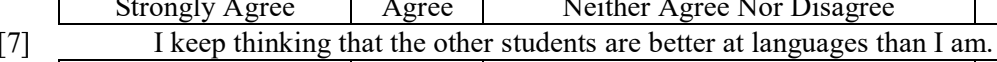

\begin{tabular}{|c|c|c|c|c|}
\hline Strongly Agree & Agree & Neither Agree Nor Disagree & Disagree & Strongly Disagree \\
\hline
\end{tabular}

[8] I am usually at ease during tests in my language class.

\begin{tabular}{|c|c|c|c|c|}
\hline Strongly Agree & Agree & Neither Agree Nor Disagree & Disagree & Strongly Disagree \\
\hline
\end{tabular}

[9] I start to panic when I have to speak without preparation in language class.

\begin{tabular}{|c|c|c|c|c|}
\hline Strongly Agree & Agree & Neither Agree Nor Disagree & Disagree & Strongly Disagree \\
\hline
\end{tabular}

[10] I worry about the consequences of failing my foreign language class. \begin{tabular}{|c|c|c|c|c|}
\hline Strongly Agree & Agree & Neither Agree Nor Disagree & Disagree & Strongly Disagree \\
\hline
\end{tabular}

[11] I don't understand why some people get so upset over foreign language classes. \begin{tabular}{|c|c|c|c|c|}
\hline Strongly Agree & Agree & Neither Agree Nor Disagree & Disagree & Strongly Disagree \\
\hline
\end{tabular}

[12] In language class, I can get so nervous I forget things I know. \begin{tabular}{|c|c|c|c|c|}
\hline Strongly Agree & Agree & Neither Agree Nor Disagree & Disagree & Strongly Disagree \\
\hline
\end{tabular}

[13] It embarrasses me to volunteer answers in my language class. \begin{tabular}{|c|c|c|c|c|}
\hline Strongly Agree & Agree & Neither Agree Nor Disagree & Disagree & Strongly Disagree \\
\hline
\end{tabular}

[14] I would not be nervous speaking the foreign language with native speakers.

\begin{tabular}{|c|c|c|c|c|}
\hline Strongly Agree & Agree & Neither Agree Nor Disagree & Disagree & Strongly Disagree \\
\hline
\end{tabular}

[15] I get upset when I don't understand what the teacher is correcting. \begin{tabular}{|c|c|c|c|c|}
\hline Strongly Agree & Agree & Neither Agree Nor Disagree & Disagree & Strongly Disagree \\
\hline
\end{tabular}

[16] Even if I am well prepared for language class, I feel anxious about it. \begin{tabular}{|c|c|c|c|c|}
\hline Strongly Agree & Agree & Neither Agree Nor Disagree & Disagree & Strongly Disagree \\
\hline
\end{tabular}

[17] I often feel like not going to my language class. \begin{tabular}{|c|c|c|c|c|}
\hline Strongly Agree & Agree & Neither Agree Nor Disagree & Disagree & Strongly Disagree \\
\hline
\end{tabular}

[18] I feel confident when I speak in foreign language class.

\begin{tabular}{|c|c|c|c|c|}
\hline Strongly Agree & Agree & Neither Agree Nor Disagree & Disagree & Strongly Disagree \\
\hline
\end{tabular}

[19] I am afraid that my language teacher is ready to correct every mistake I make. \begin{tabular}{|c|c|c|c|c|}
\hline Strongly Agree & Agree & Neither Agree Nor Disagree & Disagree & Strongly Disagree \\
\hline
\end{tabular}

[20] I can feel my heart pounding when I'm going to be called on in language class. \begin{tabular}{|c|c|c|c|c|}
\hline Strongly Agree & Agree & Neither Agree Nor Disagree & Disagree & Strongly Disagree \\
\hline
\end{tabular}

[21] The more I study for a language test, the more con- fused I get. \begin{tabular}{|c|c|c|c|c|}
\hline Strongly Agree & Agree & Neither Agree Nor Disagree & Disagree & Strongly Disagree
\end{tabular}

[22] I don't feel pressure to prepare very well for language class.

\begin{tabular}{|c|c|c|c|}
\hline Strongly Agree & Agree & Neither Agree Nor Disagree & \\
\hline I 23$]$ & always feel that the other students speak the foreign language better than I do. \\
\hline
\end{tabular} \begin{tabular}{|c|c|c|c|c|}
\hline Strongly Agree & Agree & Neither Agree Nor Disagree & Disagree & Strongly Disagree \\
\hline
\end{tabular}

[24] I feel very self-conscious about speaking the foreign language in front of other students. \begin{tabular}{|c|c|c|c|c|}
\hline Strongly Agree & Agree & Neither Agree Nor Disagree & Disagree & Strongly Disagree \\
\hline
\end{tabular}

[25] Language class moves so quickly I worry about getting left behind. \begin{tabular}{|c|c|c|c|c|}
\hline Strongly Agree & Agree & Neither Agree Nor Disagree & Disagree & Strongly Disagree \\
\hline
\end{tabular}

[26] I feel more tense and nervous in my language class than in my other classes. \begin{tabular}{|c|c|c|c|c|}
\hline Strongly Agree & Agree & Neither Agree Nor Disagree & Disagree & Strongly Disagree \\
\hline
\end{tabular}

[27] I get nervous and confused when I am speaking in my language class. \begin{tabular}{|c|c|c|c|c|}
\hline Strongly Agree & Agree & Neither Agree Nor Disagree & Disagree & Strongly Disagree \\
\hline
\end{tabular}

[28] When I'm on my way to language class, I feel very sure and relaxed. \begin{tabular}{|c|c|c|c|c|}
\hline Strongly Agree & Agree & Neither Agree Nor Disagree & Disagree & Strongly Disagree \\
\hline
\end{tabular}

[29] I get nervous when I don't understand every word the language teacher says. \begin{tabular}{|c|c|c|c|c|}
\hline Strongly Agree & Agree & Neither Agree Nor Disagree & Disagree & Strongly Disagree \\
\hline
\end{tabular}

[30] I feel overwhelmed by the number of rules you have to learn to speak a foreign language. \begin{tabular}{|c|c|c|c|c|}
\hline Strongly Agree & Agree & Neither Agree Nor Disagree & Disagree & Strongly Disagree \\
\hline
\end{tabular}

[31] I am afraid that the other students will laugh at me when I speak the foreign language.
Strongly Agree
\begin{tabular}{l|l} 
Agree & Neither Agree Nor Disagree
\end{tabular}
Disagree
Strongly Disagree

[32] I would probably feel comfortable around native speakers of the foreign language.
Strongly Agree
\begin{tabular}{l|l} 
Agree & Neither Agree Nor Disagree
\end{tabular}
Disagree
Strongly Disagree

[33] I get nervous when the language teacher asks questions which I haven't prepared in advance. \begin{tabular}{|c|c|c|c|c|}
\hline Strongly Agree & Agree & Neither Agree Nor Disagree & Disagree & Strongly Disagree \\
\hline
\end{tabular} 